\title{
Analysis of Noise Power Spectrum According to Flat-Field Correction in Digital Radiography
}

\author{
Meena Lee, Soonmu Kwon, Kwon Su Chon \\ Department of Radiological Science, Catholic University of Daegu \\ 디지털 의료영상에서 Flat-Field 보정에 따른 \\ Noise Power Spectrum 분석 \\ 이미나, 권순무, 천권수 \\ 대구가톨릭대학교 방사선학과
}

\begin{abstract}
The pixels used in a digital $\mathrm{X}$-ray detector have different sensitivities and offset values. A non-uniform image is consequently obtained. Flat-field correction was introduced to resolve this problem and carried out image preprocessing in a digital imaging system. Nevertheless, the non-uniform images caused by several reasons have been being occasionally acquired. In this study, the non-uniform images acquired in digital imaging systems were applied to flat-field correction, and NPSs were calculated and analyzed with those images before and after correction. It was confirmed that low frequency noise were effectively eliminated.
\end{abstract}

Key Words : Flat-Field Correction, Noise Power Spectrum, Digital Radiography

\section{요야}

엑스선 디지털 검출기의 내부 픽셀들은 조금씩 다른 감도와 오프셋 변동을 가지게 되어 불균일한 영상이 얻어진다. 이러한 문제를 해결하기 위해서 flat-field 보정 방법이 개발되었고, 이는 디지털 의료 영상 시스 템의 전처리 과정에서 필수적으로 수행된다. 그럼에도 불구하고 여러 가지 이유로 균일하지 않은 영상이 획득되는 경우가 종종 발생한다. 본 연구에서는 디지털 의료 영상 장비에서 획득된 불균일한 영상에 flat-field 보정을 다시 적용시켜 화질이 개선되는 것을 확인하였다. 그리고 객관적인 화질의 평가를 위해 보정 전후의 NPS를 각각 산출하여 비교하였다. 주파수 영역에서 잡음의 변화를 분석한 결과 저주파수 성 분의 잡음이 flat-field 보정 후에 크게 제거된 것을 확인할 수 있었다. 


\section{I. 서론}

1990년대의 엑스선 플랫 패널(flat panel) 검출기의 개발은 임상에서 의료 영상 시스템을 빠르게 디지털 화시켰다 ${ }^{[1]}$. 더불어 천문학 분야에서 발전되어 온 디 지털 영상 처리의 많은 기술들이 의료 영상 처리 분야 로도 확대되었다 ${ }^{[2]}$. 이러한 디지털 영상 처리 기법 중 하나인 flat-field 보정은 획득된 불균일한 디지털 신호 를 균일하게 보정하는 방법이다 ${ }^{[2,3]}$.

디지털 엑스선 검출기 내부의 픽셀들은 각각 약간 씩 다른 감도와 offset 변동을 가지고 있기 때문에 픽 셀들은 동일한 양의 엑스선을 받아도 동일한 반응을 보이지 않게 된다[3]. 그 결과 디지털 엑스선 검출기에 서 획득된 영상에서는 고정된 노이즈(구조 잡음, 전기 시스템 잡음)가 나타난다[2]. 이러한 고정된 노이즈로 인한 화질의 저하를 해결하기 위해서 디지털 의료영 상 시스템의 전처리 과정에서 flat-field 보정이 필수적 으로 수행된다. 디지털 의료영상 시스템에서 수행되는 flat-field 보정은 디지털 의료영상 장비를 세팅할 때 보 정에 필요한 데이터를 획득하여 전처리 소프트웨어 프로그램 내부에 저장하게 된다. 따라서 영상을 획득 할 때 촬영 조건에 대응하는 flat-field 보정이 전처리로 수행된다. 하지만 촬영 조건의 부적합이나 장비의 노 후화 등과 같은 여러 가지 원인으로 인해 전처리 과정 에서 flat-field 보정을 거쳤음에도 불구하고 불균일한 영상이 획득되는 경우가 발생한다나. 불균일한 영상으 로 인하여 판독에 방해가 되는 경우도 드물게 발생한 다. 본 연구에서는 flat-field 보정 알고리즘을 직접 구현 하고, 그에 따른 잡음 성분의 변화를 분석하기 위해서 NPS(Noise Power Spectrum)를 산출하였다.

\section{II. 재료 및 방법}

\section{1. 영상의 획득}

현재 병원에서 사용되고 있는 디지털 영상의 경우 에는 이미 전처리 과정에서 flat-field 보정을 거치게 된 다. 이러한 이유로 본 연구에서는 가공을 하지 않은 순수한 raw 영상 데이터를 먼저 획득하여 flat-field 보 정을 직접 적용했다. 그리고 실제 보정이 되는 것을
확인한 후 실제 병원에서 획득한 불균일한 디지털 영 상에 flat-field 보정을 실시하였다. 보정을 적용하기 전 과 후의 잡음 변화를 객관적으로 평가하기 위해서 $\mathrm{NPS}$ 를 산출하여 분석하였다. 영상의 주파수 분석을 위해서는 단순 푸리에 변환의 분석으로도 충분하다. 그러나 본 연구에서는 영상 분석의 확장성을 위하여 $\mathrm{NPS}$ 를 적용하였다. 즉 NPS는 푸리에 변환의 제곱 형 태로 주어지기 때문에 영상에서 의존도가 큰 공간주 파수를 확인하기 위해서는 NPS를 사용하여도 충분히 분석이 가능하다. Flat-field 보정 알고리즘과 NPS 산출 코드는 Visual $\mathrm{C}++$ 의 $\mathrm{MFC}$ 를 사용하여 구현하였다. NPS는 수행 속도를 고려하여 FFT(Fast Fourier Transform) 알고리즘을 적용하였다.

순수한 raw 영상을 얻기 위해서 $\mathrm{CMOS}$ (Complementary Metal-Oxide Semiconductor) 형태의 연구용 엑 스선 검출기(Dexela 1512)를 사용하였으며, 엑스선 발 생장치는 Thermo Fisher Scientific 사의 PXS10-WB-130 모델을 $30 \mathrm{kVp}, 0.2 \mathrm{~mA}, 3 \mathrm{sec}$ 의 조건에서 촬영한 영상 $(1944 \times 1536)$ 을 사용하였다. 그리고 실제 병원에서 사 용되고 있는 디지털 영상 시스템에서는 $75 \mathrm{kVp}, 100$ $\mathrm{mA}, 0.05 \mathrm{sec}$ 의 조건에서 불균일한 영상 $(3020 \times 3020)$ 을 획득하였다.

\section{Flat-field 보정}

Flat-field 보정의 방법은 크게 두 단계로 나눌 수 있다. 첫 번째는 offset 변동의 보정이고, 두 번째는 감 도와 이득 변동의 보정이다. offset 변동의 보정은 획득 한 영상에 포함된 offset과 암전류에 의한 신호를 제거 하는 것이며, 식(1)과 같이 영상을 획득하는 데 걸린 시간만큼 offset 신호를 수집하여 빼줌으로써 간단히 보정할 수 있다[3].

$$
I_{A}(x, y)=I_{A}(x, y, t)-I_{A D}(x, y, t)
$$

여기서 $\mathrm{x}, \mathrm{y}$ 는 2 차원 영상의 좌표 값을 나타내고, $\mathrm{IA}(\mathrm{x}, \mathrm{y}, \mathrm{t})$ 는 offset과 암전류에 의한 신호가 $\mathrm{t}$ 시간만큼 포함된 영상이다. 그리고 $\operatorname{IAD}(\mathrm{x}, \mathrm{y}, \mathrm{t})$ 는 엑스선의 조사 없이 offset과 암전류에 의한 신호만 $\mathrm{t}$ 시간 동안 획득한 영상이며, $\mathrm{IA}(\mathrm{x}, \mathrm{y})$ 는 offset 보정을 적용한 후의 영상이 다. 감도와 이득 변동의 보정은 다음 식(2)와 같이 
offset 보정 후의 white 영상(gain 영상)으로 보정한다[3].

$$
I_{C . A}(x, y)=I_{A}(x, y) \times \frac{\left\langle I_{W}(x, y)\right\rangle}{I_{W}(x, y)}
$$

$\mathrm{IW}(\mathrm{x}, \mathrm{y})$ 는 offset 보정을 적용시킨 후의 white 영상이 고, $<\mathrm{IW}(\mathrm{x}, \mathrm{y})>$ 는 white 영상의 평균 픽셀 값이다. 그리 고 IC.A $(\mathrm{x}, \mathrm{y})$ 는 $\mathrm{IA}(\mathrm{x}, \mathrm{y})$ 영상에 감도와 이득 변동의 보 정을 적용한 후의 결과 영상이다. Offset 보정 시 사용 되는 offset 영상(dark 영상)이나 감도와 이득 변동의 보정 시 사용되는 white 영상(gain 영상)은 오차를 최소 화하기 위해 10 장의 영상을 평균하여 사용하였다 ${ }^{[3]}$.

\section{Noise Power Spectrum(NPS) 산출}

$\mathrm{NPS}$ 는 식(3)과 같이 사진 농도의 분포 $(\mathrm{I}(\mathrm{x}, \mathrm{y}))$ 로부 터 평균값 $(\mathrm{I}(\mathrm{x}, \mathrm{y}))$ 을 뺀 변동분 $(\Delta \mathrm{I}(\mathrm{x}, \mathrm{y}))$ 을 직접 푸리에 변환하여 구하였다 ${ }^{[2,5]}$.

$$
\begin{aligned}
& \operatorname{NPS}\left(u_{n}, v_{k}\right)= \\
& \frac{\Delta x \Delta y}{M \times N_{x} \times N_{y}} \sum_{m=1}^{M} \mid \sum_{i=0}^{N_{x}-1 N_{y}-1}\left\{\left.\sum_{j=0}\left\{I\left(x_{i}, y_{j}\right)-\bar{I}\right\} e^{-2 \pi i\left(u_{n} x_{i}+v_{i} y_{j}\right)}\right|^{2}\right.
\end{aligned}
$$

이 식(3)에서 NPS(un, vk)는 주파수 영역인 u, v 공간 에서 $\mathrm{n}, \mathrm{k}$ 번째의 픽셀 값을 나타내고, $\mathrm{I}(\mathrm{xi}, \mathrm{yj})$ 는 실제 영상의 $x, y$ 에서 $i, j$ 번째의 픽셀 값을 나타낸다 $[6,7]$. 앞 에서 언급한 것처럼 I는 I(xi, yi) 영상의 평균값이며, $\mathrm{M}$ 은 평균한 영상의 개수를 나타낸다. $\mathrm{Nx}, \mathrm{Ny}, \Delta \mathrm{x}, \Delta \mathrm{y}$ 는 각각 $\mathrm{x}$ 축과 $\mathrm{y}$ 축의 픽셀 수와 픽셀 크기를 나타낸다. 본 연구에서는 한 장의 영상에서 여러 ROI (Region of Interest)로 나누어 평균하지 않고, 영상 전체를 ROI로 설정한 후 여러 장 획득 하여 평균하였다 ${ }^{[2]}$. 영상 시스 템의 성능을 평가하고자 하는 것이 아니고, 같은 영상 의 보정 전후의 차이만 비교하고자 함으로 정규화된 (normalized) NPS는 구하지 않았다.

\section{III. 결과}

\section{1. 연구용 엑스선 검출기의 flat-field 보정 적용}

전처리를 거치지 않은 $\mathrm{CMOS}$ 타입의 연구용 검출기 에서 획득된 영상은 Fig. 1 (a)와 같이 픽셀 값들이 균 일하지 않게 나타났다. Fig. 1 (b)는 위에서 설명한 flat-field 보정을 적용 시킨 후의 영상으로 전체적으로 균일하게 나타났다. Fig. 1 (c)와 (d)는 피사체를 두고 촬영한 영상을 확대한 영상이다. Flat-field 보정 전 피 사체 영상인 Fig. 1 (c)에서도 Fig. 1 (a)에서 나타난 가 로로 된 패턴과 불균일한 픽셀 패턴들이 피사체 영상 내부에서도 나타나지만 Fig. 1 (d)에서는 제거되어 나 타났다.

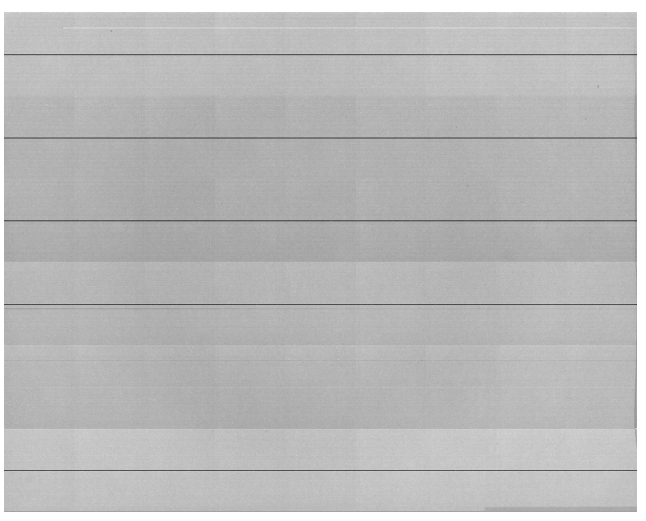

(a)

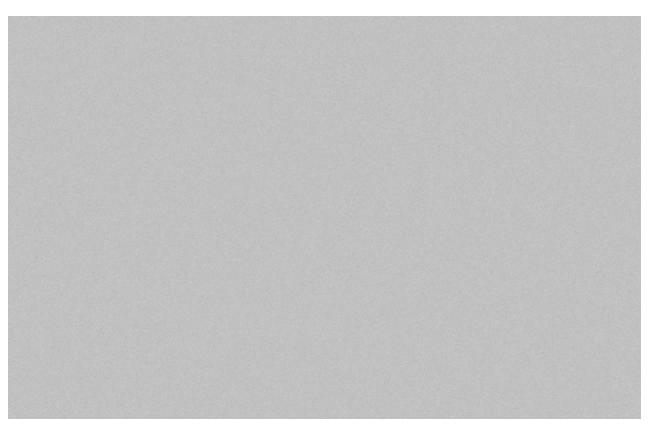

(b)

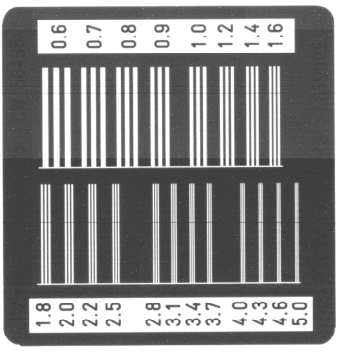

(c)

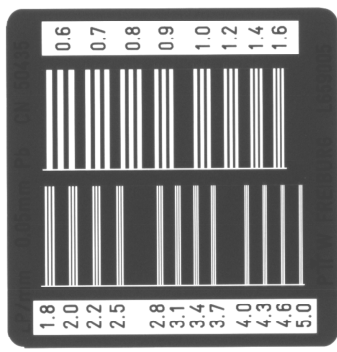

(d)
Fig. 1. Images obtained from the CMOS X-ray detector (White image before flat-field correction (a), White image after flat-field correction (b), Phantom image before flat-field correction (c), Phantom image after flat-field correction (d)). 


\section{2. 의료용 엑스선 검출기의 flat-field 보정 적용}

디지털 의료영상 장비에서 전처리 과정을 거치고 획득한 영상인 Fig. 2 (a)는 가운데 부분이 균일하게 보정되어 나타났다. 하지만 영상의 가장자리에서는 불 균일한 패턴이 관찰되었고, 특히 왼쪽 상단 모서리 부 분이 가장 불균일하게 나타났다. Flat-field 보정을 적 용시킨 결과 Fig. 2 (b)영상에서는 전체적으로 균일하 게 보정이 된 것을 육안으로 확인할 수 있다.

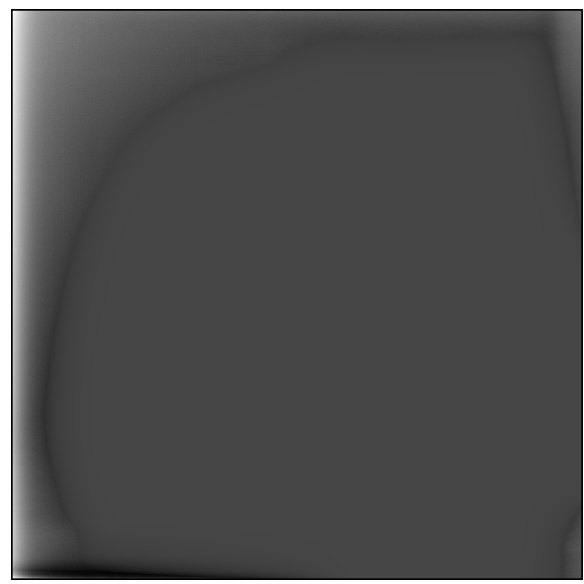

(a)

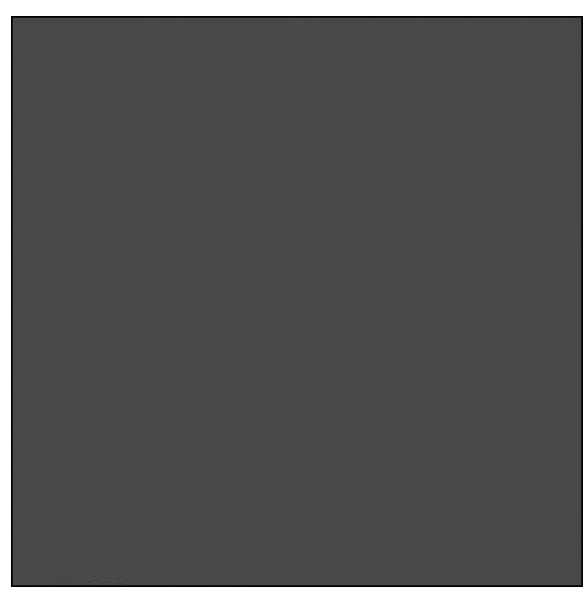

(b)

Fig. 2. Images obtained from the medical imaging system (White image before flat-field correction (a), White image after flat-field correction (b)).

Fig. 2의 flat-field 보정 전후 영상에서 각각 같은 위 치에서 $\mathrm{y}$ 축에 평행하게 프로파일을 획득하여 비교한
결과 픽셀 값의 급격한 변동이 있는 부분보다 완만한 부분이 효과적으로 보정된 것을 확인했다(Fig. 3).

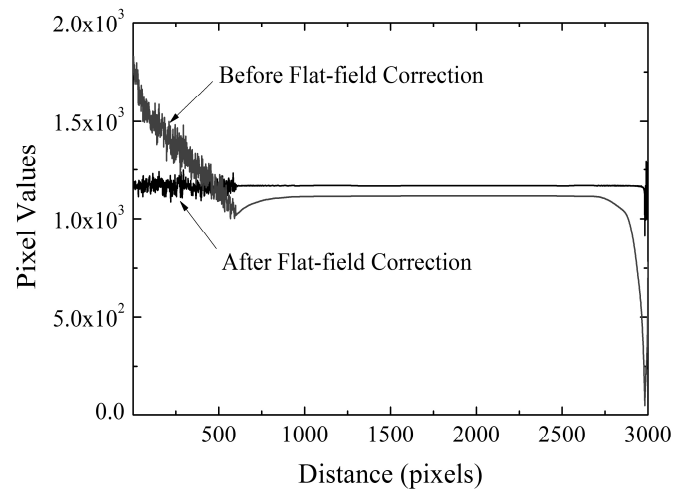

Fig. 3. Profiles at the same position for the images before and after flat-field correction.

NPS는 주파수 공간에서 잡음 성분을 나타낸 것이 기 때문에 원점에 가까울수록 저주파 성분의 잡음을 나타내고, 원점에서 멀어질수록 고주파 성분의 잡음을 나타내게 된다[8,9,10]. Fig. 4 (a)에서는 flat-field 보정 전 의 NPS로 저주파 성분과 고주파 성분의 잡음이 모두 관찰된다. Flat-field 보정 후의 NPS인 Fig. 4 (b)에서는 원점에 가까운 저주파 성분의 잡음이 제거된 것을 확 인할 수 있다. 하지만 픽셀 값의 변동이 심한 고주파 성분의 잡음은 보정 후에도 남아있는 것을 프로파일 에서 확인할 수 있었고, 보정 후의 NPS에서도 고주파 성분의 잡음이 제거되지 않은 것을 확인할 수 있었다. Fig. 4 (c)는 2차원 NPS 영상에서 획득한 정보를 이용 하여 1차원 NPS로 나타낸 그래프이다.

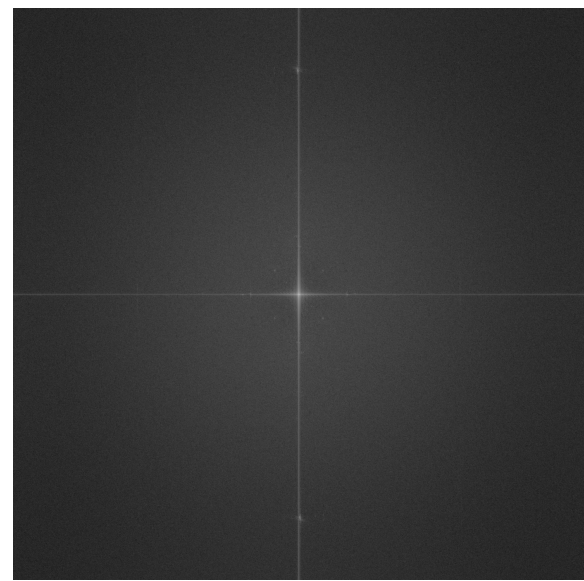

(a) 


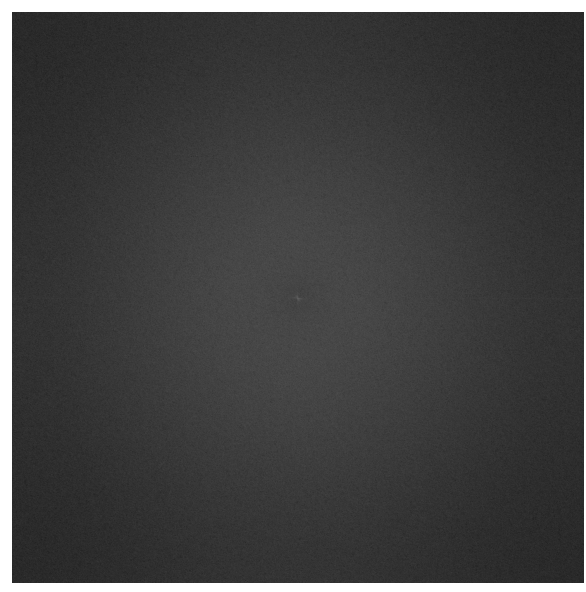

(b)

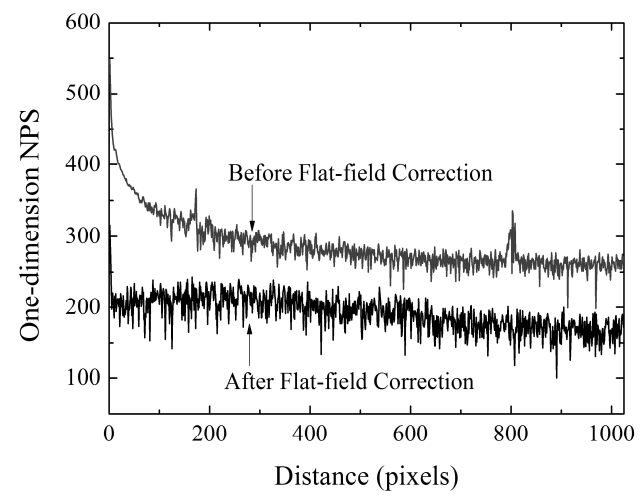

(c)

Fig. 4. NPSs for the images in the medical imaging system (Before flat-field correction (a), After flat-field correction (b), One-dimension NPSs before and after flat-field correction (c)).

\section{IV. 고찰 및 결론}

연구용 엑스선 검출기에서 획득한 raw 영상에 flat-field 보정을 직접 적용시켜봄으로써 고정된 잡음 이 제거되고, 불균일한 영상이 균일해지는 것을 확인 하였다. 피사체를 두고 촬영한 경우 대조도나 공간 분 해능에 영향을 주지 않고, 나타나는 고정된 잡음을 제 거하여 화질이 향상되는 것을 확인할 수 있었다. 따라 서 디지털 검출기에서 영상을 획득할 때 전처리로 flat-field 보정이 반드시 필요하다는 것을 확인했다. 그리고 실제 병원에서 획득한 균일하지 않은 white 영 상에도 flat-field 보정을 적용함으로써 의료영상에서 도 영상이 개선되는 것을 육안으로 알 수 있었다. 객
관적인 잡음의 평가를 위해 산출한 NPS를 통해 보정 후의 영상에서 저주파수 영역의 잡음이 효과적으로 제거된 것을 알 수 있었다. Flat-field 보정을 통해 낮 은 공간 주파수 영역의 잡음은 보정이 가능했지만 높 은 공간 주파수 영역의 잡음인 화이트 노이즈는 제거 되지 않는 것을 확인할 수 있었다. 화이트 노이즈를 제거하기 위해서는 추가적인 디노이징 필터(denoising filter)를 적용하면 개선이 가능할 것이다.

디지털 의료 영상 장비에서 전처리를 거친 영상이 불균일한 경우 화질의 저하로 영상의 판독에 영향을 미칠 수도 있다. 따라서 필요한 경우 획득한 영상에 flat-field 보정을 따로 적용시키거나 정기적인 교정 (calibration)을 통해 균일한 영상을 획득할 수 있도록 노력해야 할 것이다.

\section{감사의 글}

이 논문은 2012년도 첨단연구장비경쟁력향상사업 (No. 10038749)의 지원으로 수행되었음.

\section{참고문헌}

[1] L. Lança and A. Silva, "Digital radiography detectors-A technical overview: Part 1," Radiography, Vol. 15, pp.58-62, 2009 .

[2] J. T. Bushberg, The essential physics of medical imaging, Lippincott Williams \& Wilkins, 2011.

[3] J. A. Seibert, J. M. Boone, and K. K. Lindfors, "Flat-field correction technique for digital detectors," Medical Imaging, Vol. 3336, pp.348-354, 1998.

[4] D. Davidson, C. Fröjdh, V. O'Shea, H. Nilsson, and M. Rahman, "Limitations to flat-field correction methods when using an X-ray spectrum," Nuclear Instruments and Methods in Physics Research Section A: Accelerators, Spectrometers, Detectors and Associated Equipment, Vol. 509, pp.146-150, 2003.

[5] K. M. Hanson, "A simplified method of estimating noise power spectra," Medical Imaging, Vol. 3336, pp.243-250, 1998.

[6] G. J. Whitman and T. M. Haygood, Digital Mammography: A Practical Approach, Cambridge University Press, 2012.

[7] I. A. Cunningham, "Degradation of the detective quantum efficiency due to a nonunity detector fill factor," Medical Imaging, Vol. 3032, pp.22-31, 1997. 
[8] J. H. Siewerdsen, L. E. Antonuk, Y. El-Mohri, J. Yorkston, W. Huang, and I. A. Cunningham, "Signal, noise power spectrum, and detective quantum efficiency of indirect-detection flat-panel imagers for diagnostic radiology," Medical Physics, Vol. 25, pp.614-628, 1998.

[9] A. Kuhls-Gilcrist, A. Jain, D. R. Bednarek, K. R. Hoffmann, and S. Rudin, "Accurate MTF measurement in digital radiography using noise response," Medical Physics, Vol. 37, pp.724-735, 2010.

[10] L. Lança and A. Silva, "Digital radiography detectors-A technical overview: Part 2," Radiography, Vol. 15, pp. 134-138, 2009. 